\title{
Applications of Mathematics
}

Peter Maličký; Marianna Maličká

On the computation of Aden functions

Applications of Mathematics, Vol. 36 (1991), No. 1, 2-8

Persistent URL: http://dml.cz/dmlcz/104439

\section{Terms of use:}

(C) Institute of Mathematics AS CR, 1991

Institute of Mathematics of the Czech Academy of Sciences provides access to digitized documents strictly for personal use. Each copy of any part of this document must contain these Terms of use.

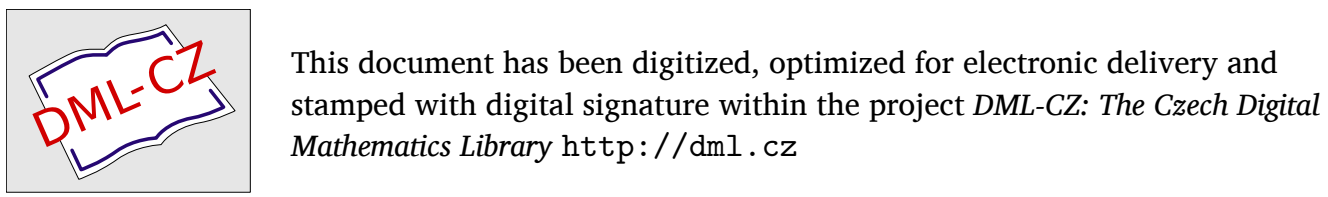




\title{
ON THE COMPUTATION OF ADEN FUNCTIONS
}

\author{
Peter MaličKú, Marianna MaličKá \\ (Received December 13, 1988)
}

Summary. The paper deals with the computation of Aden functions. It gives estimates of errors for the computation of Aden functions by downward reccurence.

Keywords: Aden functions, continued fraction, Mie coefficients.

AMS Classification: 65D20, 33A40, 78A45.

Aden functions $D_{n}$ are used in the theory of light scattering on sphere particles $[2,3,4]$.

Aden function $D_{n}(z)$ of the complex argument $z$ is defined by upward reccurence:

$$
\begin{aligned}
& D_{0}(z)=\operatorname{cotg} z \\
& D_{n+1}(z)=\frac{1}{\frac{n+1}{z}-D_{n}(z)}-\frac{n+1}{z} .
\end{aligned}
$$

The computation of $D_{n}(z)$ by upward reccurence becomes unstable when $n$ is large (more exactly, when $n>|z|-\frac{3}{2}$ ).

To compute $D_{n}$ for large $n$, downward reccurence is used. We put

$$
\begin{aligned}
& \widetilde{D}_{N}(z)=0 \text { for sufficiently large } N, \text { and } \\
& \widetilde{D}_{n}(z)=\frac{n+1}{z}-\frac{1}{\frac{n+1}{z}+\widetilde{D}_{n+1}(z)} \text { for } 0 \leqq n<N .
\end{aligned}
$$

$\left(\widetilde{D}_{n}\right.$ is taken as the approximation of $D_{n}$.)

The present paper gives a method how to determine $N$ when $D_{n}(z)$ must be computed with a given accuracy.

The analysis of errors is easier if relation (3) is replaced by

$$
\widetilde{D}_{N}(z)=\frac{N+1}{z} \text {. }
$$

This approximation is suggested by relations (13) and (16) below, see also [4]. 


\section{PROPERTIES OF ADEN FUNCTIONS}

Aden functions $D_{n}$ are closely related to Riccati-Bessel functions, which are defined by formulas

(6)

$$
\begin{aligned}
& \psi_{0}(z)=\sin z, \\
& \psi_{1}(z)=\frac{\sin z}{z}-\cos z, \\
& \psi_{n+1}(z)=\frac{2 n+1}{z} \psi_{n}(z)-\psi_{n-1}(z) .
\end{aligned}
$$

Denote

(9)

$$
C_{n}(z)=\frac{\psi_{n+1}(z)}{\psi_{n}(z)} .
$$

Then (6) -(8) imply

$$
\begin{aligned}
& C_{0}(z)=\frac{1}{z}-\operatorname{cotg} z \\
& C_{n}(z)=\frac{2 n+1}{z}-\frac{1}{C_{n-1}(z)}, \text { and } \\
& C_{n-1}(z)=\frac{1}{\frac{2 n+1}{z}-C_{n}(z)} .
\end{aligned}
$$

Using induction, (1), (2), (10) and (11) it is easy to show that

$$
D_{n}(z)=\frac{n+1}{z}-C_{n}(z) \text { for all } n .
$$

The Riccati-Bessel function $\psi_{n}$ may be expressed as the series

$$
\psi_{n}(z)=\sum_{k=0}^{\infty} \frac{(-1)^{k} z^{2 k+n+1}}{(2 k) ! !(2 k+2 n+1) ! !}
$$

(see [1], p. 256).

For fixed $z$ and $n \rightarrow \infty$ (14) gives

$$
\psi_{n}(z) \sim \frac{z^{n+1}}{(2 n+1) ! !},
$$

which together with (9) yields

$$
C_{n}(z) \sim \frac{z}{2 n+3} .
$$

(The symbol $\sim$ means that the limit of the quotient of the both sides is 1 .) 
Relation (16) shows that $\left|C_{n}(z)\right|<1$ for sufficiently large $n$.

Now, suppose that $n>|z|-\frac{3}{2}$ and $\left|C_{n+1}(z)\right|<1$. Using (12) we have

$$
\left|C_{n}(z)\right|=\frac{1}{\left|\frac{2 n+3}{z}-C_{n+1}(z)\right|} \leqq \frac{1}{\left|\frac{2 n+3}{z}\right|-\left|C_{n+1}(z)\right|}<\frac{1}{2-1}=1 .
$$

It means that

$$
\left|C_{n}(z)\right|<1 \text { for all } n>|z|-\frac{3}{2} .
$$

\section{ERROR ESTIMATES}

We assume that a complex number $z$ is fixed, and we write $D_{n}, C_{n}$ and $\widetilde{D}_{n}$ instead of $D_{n}(z), C_{n}(z)$ and $\widetilde{D}_{n}(z)$. Observe that the computation of $D_{n}$ by formulas $(5)$ and (4) may be replaced by

$$
\begin{aligned}
& \widetilde{C}_{N}=0, \\
& \widetilde{C}_{n}=\frac{1}{\frac{2 n+3}{z}-\widetilde{C}_{n+1}} \text { for } 0 \leqq n<N, \text { and } \\
& \widetilde{D}_{n}=\frac{n+1}{z}-\widetilde{C}_{n} .
\end{aligned}
$$

The following proposition characterizes the behaviour of errors when $D_{n}$ are computed by downward reccurence.

Proposition 1. If $N>n>|z|-\frac{3}{2}$ then

$$
\left|D_{n}-\tilde{D}_{n}\right|<\left|D_{n+1}-\tilde{D}_{n+1}\right| \text {. }
$$

Proof. Relations (13) and (20) imply

$$
D_{n}-\widetilde{D}_{n}=\widetilde{C}_{n}-C_{n} \text {. }
$$

Therefore, it is sufficient to prove

$$
\left|\widetilde{C}_{n}-C_{n}\right|<\left|C_{n+1}-\widetilde{C}_{n+1}\right| \text {. }
$$

Relations (19) and (12) give

$$
\begin{aligned}
& \widetilde{C}_{n}-C_{n}=\frac{1}{\frac{2 n+3}{z}-\tilde{C}_{n+1}}-\frac{1}{\frac{2 n+3}{z}-C_{n+1}}= \\
& =\frac{\tilde{C}_{n+1}-C_{n+1}}{\left(\frac{2 n+3}{z}-\tilde{C}_{n+1}\right)\left(\frac{2 n+3}{z}-C_{n+1}\right)}=C_{n} \widetilde{C}_{n}\left(\tilde{C}_{n+1}-C_{n+1}\right) .
\end{aligned}
$$


We obtain

$$
\left|\tilde{C}_{n}-C_{n}\right|=\left|C_{n}\right| \cdot\left|\widetilde{C}_{n}\right| \cdot\left|\tilde{C}_{n+1}-C_{n+1}\right|
$$

The inequality

$$
\left|\tilde{C}_{n}\right|<1 \text { for } N \geqq n>|z|-\frac{3}{2}
$$

may be proved in the same way as (17). Now, (23) follows from (24), (17) and (25).

Remark. We have also the following inequality for relative errors of $C_{n}$ :

$$
\begin{aligned}
& \left|\frac{\widetilde{C}_{n}}{C_{n}}-1\right|=\frac{1}{\left|C_{n}\right|}\left|\widetilde{C}_{n}-C_{n}\right|=\frac{1}{\left|C_{n}\right|}\left|C_{n}\right|\left|\tilde{C}_{n}\right|\left|\tilde{C}_{n+1}-C_{n+1}\right|= \\
& =\left|\tilde{C}_{n}\right|\left|C_{n+1}\right|\left|\frac{\tilde{C}_{n+1}}{C_{n}}-1\right|<\left|\frac{\widetilde{C}_{n+1}}{C_{n+1}}-1\right|
\end{aligned}
$$

whenever $N>n>|z|-3 / 2$.

However, the behaviour of relative errors of $D_{n}$ is somewhat complicated and we consider only absolute errors.

Now, suppose that for a fixed $n_{0}>|z|-3 / 2$ we want to obtain $\widetilde{D}_{n_{0}}$ such that $\left|\widetilde{D}_{n_{0}}-D_{n_{0}}\right|<\Delta$, where $\Delta$ is prescribed. The question is, how large must $N$ be chosen.

Let $N \geqq n_{0}$ be fixed. Denote

$$
k=N-n_{0} .
$$

Relations (12) and (19) give

$$
C_{n_{0}}=\frac{1}{\frac{2 n_{0}+3}{z}-\frac{1}{\frac{2 n_{0}+5}{z}-\frac{1}{\frac{2 n_{0}+2 k+1}{z}-C_{n_{0}+k}}}}
$$

and

$$
\tilde{C}_{n_{0}}=\frac{1}{\frac{2 n_{0}+3}{z}-\frac{1}{\frac{2 n_{0}+5}{z}-\frac{1}{\frac{2 n_{0}+2 k+1}{z}-\tilde{C}_{n_{0}+k}}} .}
$$

Note that $\widetilde{C}_{n_{0}+k}=0$ by $(18)$ and $(26)$. 
Theory of continued fractions (see [5], pp. 39-49) shows that

$$
\widetilde{C}_{n_{0}}=\frac{P_{k}}{Q_{k}} \text { and }
$$

$$
C_{n_{0}}=\frac{R_{k}}{S_{k}}
$$

where the numbers $P_{k}, Q_{k}, R_{k}$ and $S_{k}$ are defined by

(29.a) $P_{0}=0$,

(30.a) $Q_{0}=1$,

(29.b) $\quad P_{1}=1$,

(30.b) $Q_{1}=\frac{2 n_{0}+3}{z}$,

(29.c) $\quad P_{j}=\frac{2 n_{0}+2 j+1}{z} P_{j-1}-P_{j}$,

(30.c) $Q_{j}=\frac{2 n_{0}+2 j+1}{z} Q_{j-1}-Q_{j-2}$

for $j>1$,

$$
R_{k}=\left(\frac{2 n_{0}+2 k+1}{z}-C_{n_{0}+k}\right) P_{k-1}-P_{k-2},
$$

$$
S_{k}=\left(\frac{2 n_{0}+2 k+1}{z}-C_{n_{0}+k}\right) Q_{k-1}-Q_{k-2} .
$$

Using (29.c), (31), (30.c) and (32) we have

$$
\begin{aligned}
& R_{k}=P_{k}-C_{n_{0}+k} P_{k-1}, \\
& S_{k}=Q_{k}-C_{n_{0}+k} Q_{k-1} .
\end{aligned}
$$

Relations (22), (27), (28), (33) and (34) imply

$$
\begin{aligned}
& \tilde{D}_{n_{0}}-D_{n_{0}}=C_{n_{0}}-\tilde{C}_{n_{0}}=\frac{R_{k}}{S_{k}}-\frac{P_{k}}{Q_{k}}= \\
& =\frac{Q_{k}\left(P_{k}-C_{n_{0}+k} P_{k-1}\right)-P_{k}\left(Q_{k}-C_{n_{0}+k} Q_{k-1}\right)}{\left(Q_{k}-C_{n_{0}+k} Q_{k-1}\right) Q_{k}}= \\
& =\frac{C_{n_{0}+k}\left(P_{k} Q_{k-1}-P_{k-1} Q_{k}\right)}{Q_{k}\left(Q_{k}-C_{n_{0}+k} Q_{k-1}\right)} .
\end{aligned}
$$

The equality

$$
P_{k} Q_{k-1}-P_{k-1} Q_{k}=1
$$

follows from (29), (30) by induction.

Hence

$$
\left|\widetilde{D}_{n_{0}}-D_{n_{0}}\right|=\frac{\left|C_{n_{0}+k}\right|}{\left|Q_{k}\right|\left|Q_{k}-C_{n_{0}+k} Q_{k-1}\right|} .
$$

6 
From (30) it is easy to obtain

$$
\begin{aligned}
& \left|Q_{j}\right| \geqq\left(\frac{2 n_{0}+2 j+1}{|z|}-1\right)\left|Q_{j-1}\right|>\left|Q_{j-1}\right| \text { and } \\
& \left|Q_{j+1}\right|-\left|Q_{j}\right|>\left|Q_{j}\right|-\left|Q_{j-1}\right|
\end{aligned}
$$

whenever $n_{0}>|z|-\frac{3}{2}$ and $j \geqq 1$.

Using (35), (36) and (17) we have

$$
\left|\widetilde{D}_{n_{0}}-D_{n_{0}}\right|<\frac{1}{\left|Q_{k}\right|\left(\left|Q_{k}\right|-\left|Q_{k-1}\right|\right)} .
$$

Theorem 1. Let a complex number $z$ and a natural number $n_{0}>|z|-\frac{3}{2}$ be fixed. For any positive $\Delta$ there exists a natural number $k$ such that

$$
\frac{1}{\left|Q_{k}\right|\left(\left|Q_{k}\right|-\left|Q_{k-1}\right|\right)}<\Delta
$$

If the computation of $\tilde{D}_{n}$ by (4) and (5) is started from $N=n_{0}+k$, then

$$
\left|\widetilde{D}_{n}-D_{n}\right|<\Delta \quad \text { whenever } n_{0} \geqq n>|z|-\frac{3}{2} .
$$

Proof. The existence of $k$ such that (39) holds, follows from (36) and (37). (To find this natural number $k$ it is necessary to compute $Q_{k}$ by relations (30.a)-(30.c) until relation (39) is satisfied.) Relations (21), (38) and (39) give (40).

The method presented here was tested on EC 1033 by the authors. For a given complex number $z$ and a natural number $n_{0}>|z|-\frac{3}{2}$ we have found $N$ such that $\left|\widetilde{D}_{n}-D_{n}\right|<10^{-13}$ whenever $n_{0} \geqq n>|z|-\frac{3}{2}$. The value $\widetilde{D}_{0}$ was compared with $\operatorname{cotg} z$. No rounding error was observed. Partial results are summarized in the table.

Table

\begin{tabular}{crr}
\hline$z$ & $n_{0}$ & $N$ \\
\hline $1+0,1 i$ & 3 & 9 \\
$1+i$ & 5 & 11 \\
$1+10 i$ & 15 & 26 \\
$10+i$ & 15 & 26 \\
$10+10 i$ & 20 & 32 \\
$10+100 i$ & 150 & 163 \\
$100+10 i$ & 150 & 165 \\
$100+100 i$ & 200 & 214 \\
$100+1000 i$ & 1200 & 1215 \\
$1000+10 i$ & 1100 & 1132 \\
$1000+100 i$ & 1200 & 1224 \\
$1000+1000 i$ & 1800 & 1816 \\
\hline
\end{tabular}


[1] M. Abramowitz, I. A. Stegun: Handbook of mathematical functions with formulas, graphs and mathematical tables. Washington, National Bureau of Standards, 1964 (Russian translation, Moskva, Nauka, 1979).

[2] C.F. Bohren, D. R. Huffman: Absorption and Scattering of Light by Small Particles. J. Wiley, New York 1983 (Russian translation, Moskva, Mir, 1986).

[3] D. Deirmendjian: Electromagnetic Scattering on Spherical Polydispersions. Elsevier, New York 1969 (Russian translation, Moskva, Mir, 1971).

[4] Ju. A. Il'jin, S. A. Starcev: K voprosu o vyčislenii formul Mi na EVM. Kratkije soobščenija po fizike, (1984), N. 5, 34-37.

[5] W. B. Jones, W. J. Thron: Continued Fractions. Analytic Theory and Applications. AddisonWesley, London 1980 (Russian translation, Moskva, Mir, 1985).

Súhrn

VÝPOČET ADENOVÝCH FUNKCIÍ

Peter MaličKú, Marianna MaličKá

Článok sa zaoberá výpočtom Adenových funkcií spätnou rekurziou. Sú v ňom odhadnuté chyby pri numerických výpočtoch.

Authors' addresses: RNDr. Peter Maličký, CSc., Katedra matematiky VVTŠ, 03119 Liptovský Mikuláš; RNDr. Marianna Maličká, Katedra mikroelektroniky a laserovej techniky VVTŠ, 03119 Liptovský Mikulás. 